\title{
A Case Report of Spontaneous Pneumothorax in the 2019 Novel Coronavirus-Infected Pneumonia
}

\author{
Yunhu Pan ( 18750975908@163.com ) \\ 907 hospital of PLA https://orcid.org/0000-0001-7172-8267
}

\section{Shuo Wei}

Fujian provincial of hospital

\section{Guang Chen}

907 hospital of PLA

\section{Yuancheng Hong}

910th Hospital of PLA

\section{Case Report}

Keywords: COVID-19, dyspnea, pneumothorax, respiratory failure, ECMO

Posted Date: June 12th, 2020

DOI: https://doi.org/10.21203/rs.3.rs-34276/v1

License: (9) This work is licensed under a Creative Commons Attribution 4.0 International License. Read Full License 


\section{Abstract}

Background: COVID-19,which pathogen virus officially named SARS-CoV-2, started in China Wuhan city and so far rapidly spread to a global outbreak. Since the lung is the main lesion organ for virus invasion, Chest CT is strongly recommended in COVID-19 on either initial diagnosis and follow-up.Multiple patchy shadows and ground glass opacity of bilateral lung are typical features of CT scan,and spontaneous pneumothorax appeared in the early onset of COVID-19 is rare.

Case Presentation: We reported one case of spontaneous pneumothorax in the early onset of COVID-19, chest CT showed only a small amount of pneumothorax were seen in the right lobe.After receiving 4 days of treatment, re-examination chest CT shows right pneumothorax disappeared, but the patient was clinically worse, and progressive multiple diffuse consolidation. Although treatment with extracorporeal membrane oxygenator,the patient died 15 days after admission.

Conclusion: Spontaneous pneumothorax in the early stages of COVID-19 is rare,which imaging features differ from other lung diseases complicated with pneumothorax,such as COPD.More than we usually know,the improvement of pneumothorax and the outcome of COVID-19 may be inconsistent.

\section{Introduction}

COVID-19, which pathogen virus officially named SARS-CoV-2, started in China Wuhan city and so far rapidly spread to a global outbreak $(1,2)$. Since the lung is the main lesion organ for virus invasion, multiple patchy shadows and ground glass opacity of bilateral lung are typical features of CT scan (3) ,and pneumothorax appeared in the early onset of COVID-19 is rare. Here we report a fatal case of COVID-19 with spontaneous pneumothorax.

\section{Case Presentation}

A 67-year-old woman presented to the hospital with a 15-day history of low-grade fever,fatigue,cough and progressive dyspnea. She had never smoked and denied any chronic underlying illness. At admission, physical examination revealed a body temperature of $37.6^{\circ} \mathrm{C}\left(99.68^{\circ} \mathrm{F}\right)$, respiratory rate of 26 breaths per minute, pulse of 92 beats per minute, and $66 \%$ oxygen saturation in ambient air. Lung auscultation revealed coarse breath sounds of both lungs. Laboratory studies showed white blood cell count $9.0 \times$ $10^{9} / \mathrm{L}$. The white blood cell differential count showed $82.9 \%$ neutrophils and $11.1 \%$ lymphocyte. There were elevated blood levels for C-reactive protein $(24.07 \mathrm{mg} / \mathrm{L}$; normal range, $0-4 \mathrm{mg} / \mathrm{L})$, and D-dimer $(7890 \mathrm{ng} / \mathrm{mL}$; normal range, $0-500 \mathrm{ng} / \mathrm{mL}$ ). Chest CT showed multiple diffuse consolidation and groundglass opacities in bilateral lungs. A small amount of pneumothorax were seen in the right lobe (Figure, A) . A nucleic acid amplification test was positive for severe acute respiratory syndrome coronavirus 2 QSARS-CoV-2 $\triangle$ by nasopharyngeal swab. The diagnosis of severe 2019 novel coronavirus-infected pneumonia (COVID-19) was made. After receiving 4 days of treatment, the patient was clinically worse, reexamination chest CT shows right pneumothorax disappeared,but progressive multiple diffuse 


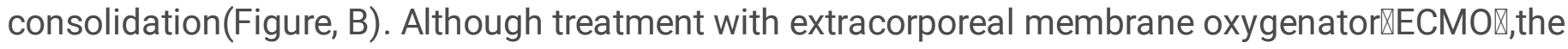
patient died 15 days after admission.

\section{Discussion}

China and the rest of the world are experiencing an outbreak of a novel coronavirus known as SARS-CoV2 that caused a public health emergency of international concern (4). The most appropriate treatment regimens for COVID-19 still have not been firmly established despite several new agents that are currently under investigation. Since the lung is the main lesion organ for virus invasion,chest CT is strongly recommended in COVID-19 on either initial diagnosis and follow-up.Most common features of CT scan is bilateral ground glass opcity in the disease,atypical imaging features including pleural effusion, lymphadenopathy and bronchial wall thickening $₫ 5 \rrbracket$,and spontaneous pneumothorax was rare,as pneumothorax is well-known complications of mechanical ventilation when support treatment for COVID19.

We reported one case of spontaneous pneumothorax in the early onset of COVID-19, the virus damage to the alveoli and persistent cough in COVID-19 can be the causative factor for spontaneous pneumothorax in this patient.Though spontaneous pneumothorax occurs in the initial diease is seldom seen. it has a significant impact on treatment and prognosis, and early identification of pneumothorax is critical. When pneumothorax accompanied by respiratory failure,correcting hypoxia can be tricky. In view of exercising noninvasive or invasive ventilator can aggravate pneumothorax, ECMO may be the appropriate therapy .Calamitously,if the disease is critical, the chances of survival are slim.Our case suggests that lung tissue compression may not be severe in the presence of pneumothorax in COVID-19 compared with other diseases,such as COPD. and the improvement of pneumothorax and the outcome of COVID-19 may be inconsistent.

\section{Conclusion}

Spontaneous pneumothorax in the early stages of COVID-19 is rare,which imaging features differ from other lung diseases complicated with pneumothorax,such as COPD.More than we usually know,the improvement of pneumothorax and the outcome of COVID-19 may be inconsistent. When COVID-19 complicated with pneumothorax, it can have an impact on treatment, especially occurs with respiratory failure,which correlates with poor outcome of COVID-19.

\section{Abbreviations}

COVID-19®2019 Novel Coronavirus-Infected Pneumonia\SARS-CoV-2邓severe acute respiratory syndrome coronavirus $2 \triangle \mathrm{ECMO}$ \extracorporeal membrane oxygenatorखCOPD囚chronic obstructive pulmonary disease】

\section{Declaration}




\section{Acknowledgements}

We thank all the hospital staff members ( Liu J,He SQ囚Liang JJ, Tang M, Wang Q, Cai YL, Yang QY,Ma X, Lin MF,Gan ZH) for their efforts in collecting the information that was used in this study.

\section{Authors' contributions}

YP and GC had roles in clinical management, CHcontributed to data collection s and data entry. YP and SW also wrote the manuscript. All authors reviewed and approved the final version of the manuscript.

\section{Funding}

This project was supported by the Key Research Project of Nanjing Military Area Command (grant no. 14ZD32)

\section{Availability of data and materials}

Not applicable.

\section{Ethics approval and consent to participate}

This study has been approved by the Ethics Committee of Huoshenshan Hospital (No. HSS141).

\section{Consent for publication}

Not applicable.

\section{Competing interest}

The authors declare that they have no competing interests.

\section{Reference}

1. Huang C, Wang Y, Li X, Ren L, Zhao J, Hu Y, et al. Clinical features of patients infected with 2019 novel coronavirus in Wuhan, China. Lancet,2020; 395(10223): 497-506.

2. Lu R, Zhao X, Li J, Niu P, Yang B, Wu H, et al. Genomic characterisation and epidemiology of 2019 novel coronavirus: implications for virus origins and receptor binding. Lancet 2020; 395(10223): 565- 
3. Wang D, Hu B, Hu C, Zhu F, Liu X, Zhang J,et al. Clinical characteristics of 138 hospitalized patients with 2019 Novel Coronavirus-Infected Pneumonia in Wuhan, China.JAMA. 2020 ;323(11):10611069.

4. Chen N, Zhou M, Dong X, Qu J, Gong F, Han Y, et al. Epidemiological and clinical characteristics of 99 cases of 2019 novel coronavirus pneumonia in Wuhan, China: a descriptive study. Lancet2020; 395(10223):507-513.

5. Salehi S, Abedi A, Balakrishnan S, Gholamrezanezhad A. Coronavirus disease 2019 (COVID-19): a systematic review of imaging findings in 919 patients. AJR AM J Roentgenol 2020;14(3):1-7.

\section{Figures}




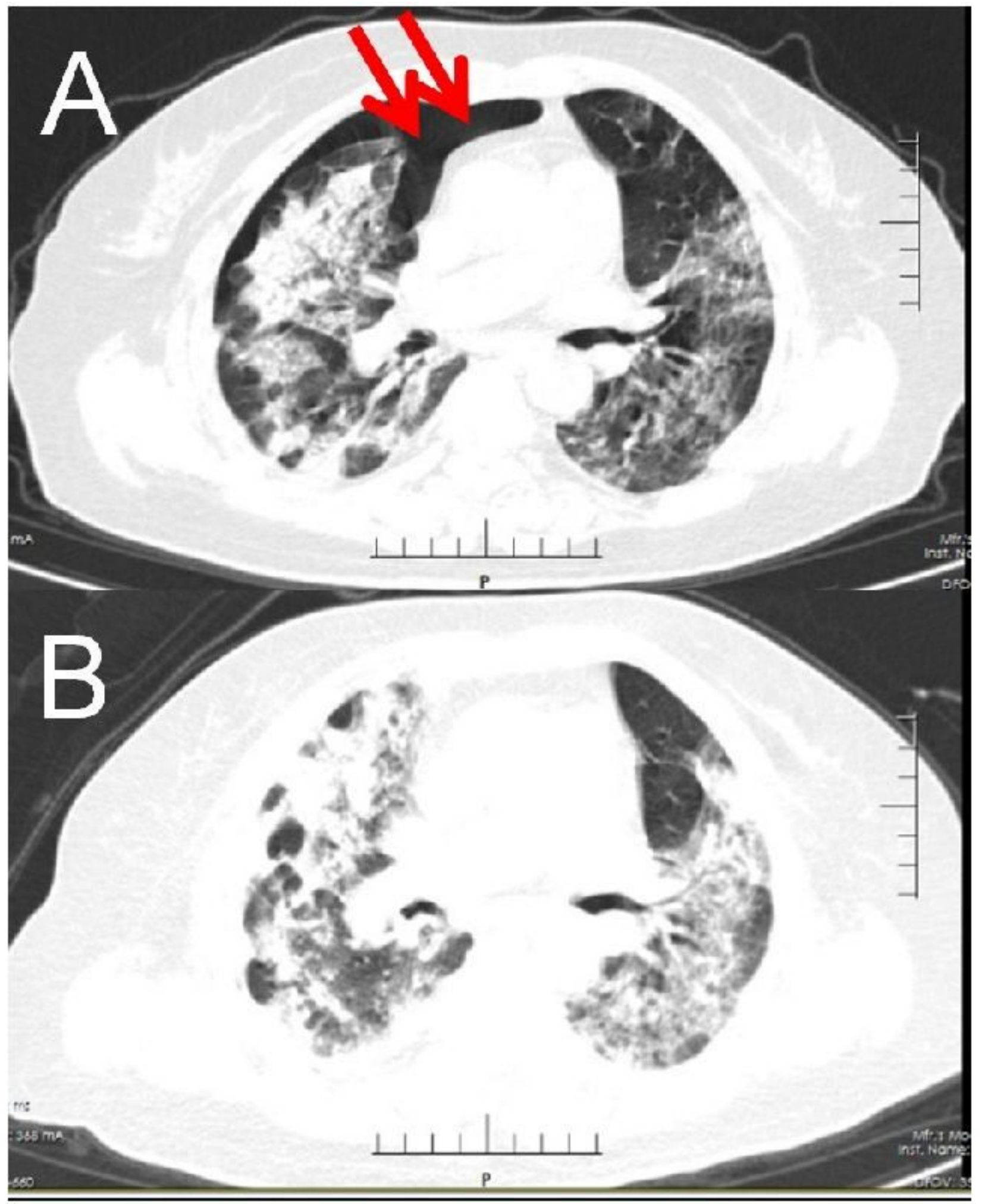

\section{Figure 1}

Chest CT images in a 67-year-old woman. A,Image shows multiple diffuse consolidation and groundglass opacities in bilateral lungs. A small amount of pneumothorax are seen in the right lobe(red arrow). B, Image obtained 4 days after follow-up shows right pneumothorax disappeared,but progressive multiple diffuse consolidation. 